\title{
Does the COVID-19 pandemic affect social-ecological resilience of organic rice production system in Chiang Mai Province, Thailand?
}

\author{
Chaiteera Panpakdee ${ }^{1,{ }^{*}}$ and Fakjit Palinthorn ${ }^{1}$ \\ 1 Department of Agricultural Extension and System Approaches, Faculty of Agriculture, Khon Kaen \\ University, Khon Kaen, 40002, Thailand. \\ * Corresponding author: Email: chaitpa@kku.ac.th
}

\begin{abstract}
The purpose of this study was to investigate how the COVID-19 pandemic affects the organic rice production system in four districts of Chiang Mai Province. Eight organic farmers were purposefully chosen as informants because they have possessed forty-seven resilience components (SERCS) needed to cope with all kinds of social-ecological change. They were asked using a structured questionnaire to assign each SERC's contribution value before and after the COVID-19 pandemic, in which each time scoring must be coupled with entailed explanations. Then, the paired samples t-test was run to compare such means of SERCs' contribution values to examine whether their organic rice production's resilience was affected by the pandemic and how. Results showed the means of SERCs before and after the pandemic have no significant difference as the $p$-value is 1.00 at the $95 \%$ confidence interval. This meant the pandemic does not influence the organic rice production's social-ecological resilience. But several practices and qualifications were found varying from the original to make production more suitable. The dependence on household labor and that on mutual labor exchange were respectively increased and decreased in their roles in resilience building. Labor availability was interrupted by the social distancing protocol that had restricted people from gathering. Besides, the household accounts recording was adopted more than usual for being seen as a solution to improving the household economy during the time of financial vulnerability. Importantly, relying on local goods was remarkably recognized for increased importance. This was an attempt to get access to materials possibly free from the COVID-19 contamination because of the absent transportation. These findings provide two key interests. They can be applied as a framework not only to strengthen agricultural resilience but also to propose a blueprint of coping mechanisms against the pandemic at a mass scale.
\end{abstract}

Keywords: organic rice production; resilience; social-ecological resilience; COVID-19; Chiang Mai

\section{Introduction}

A current worldwide trend towards the promotion of organic rice has been supported in Thailand since the late 1990s strategically propelled by the 8th National Economic and Social Development Plan (1997-2001). This plan is the first national framework that specifically describes organic rice as sustainable farming in its capacity to offer safe staple food to the population (Anderson and Martin, 2009). Besides, organic rice proposes the holistic benefit associated with ecologically sound, economically viable, and socially responsible consequences (Rousseau and Vranken, 2013). Since then, the schemes of organic rice promotion have therefore become a major theme for agricultural development. Thailand has aimed at converting $20 \%$ of arable land to organic agriculture and reducing the use of chemical substances and synthetic fertilizers by at least $50 \%$ (Rattanasuteerakul and Thapa, 2012).

In Chiang Mai, organic rice grown to meet various quality standards has been popularized since the early 1990s (DOAE, 2013). The farming of organic rice for the market at the beginning stemmed from the efforts of the non-government organizations (NGOs), government agencies, and academic institutions that incidentally had a common mission of assisting the growers with relevant knowledge, inputs, and market outlets to enable them to produce safe food, get a premium price 
including the organic certification for their output, and have better livelihoods (Green Net, 2014). Consequently, organic rice networks have been established within the province to exchange skills and strengthen production and marketing management capability (Limnirankul and Gypmantasiri, 2011). Meanwhile, Chiang Mai has geographic features favorable for the production of organic rice and other agricultural products (Panpakdee and Limnirankul, 2018). The province is also a renowned tourist destination for its unique natural resources and cultures that attract a considerable number of tourists, both domestic and international to visit. These all are opportunities for organic farmers, particularly the marginal ones, to attain economic viability and sustainable development (Pattanapant and Shivakoti, 2009; Boone et al., 2019).

In ordinary circumstances, growing organic rice is an arduous enterprise. The holistic production management is required to comply with strict organic farming regulations. The output quality has to meet the demand of niche consumers who are willing to pay a more expensive price for $100 \%$ organic purity as driven in part by public anxiety over food contamination (Stuart and Werayutwattana, 2017). These responsibilities are often added to increase the size of drawback with the deforestation happened annually within the province that not only generates air pollution and halt of tourism activities but also the loss of soil nutrients which directly affects organic rice production. Instead of shifting to the other agricultural system that is more convenient, most organic farmers still keep operating organic production by taking adaptation to mitigate the constraints as their goal is oriented toward quality food and environmentally sound farming (Ratanapongsai, 2020).

With the outbreak of COVID-19, the business of most economic sectors has been hard hit and that of organic rice production is not an exception. Particularly in Chiang Mai Province, organic farmers are reportedly severely struggling and confronting massive challenges. They have difficulty selling their output due to the closure of marketplaces and the perturbed logistics consequential to the use of various measures to combat the pandemic (Bouttes et al., 2018; WWF, 2020). Even the markets are permitted to be re-opened, the business would be vulnerable as consumers are restricted to certain food sources. Most importantly, many processes of organic rice production primarily rely on human labor to manage some dedicated tasks such as weeding, watering and controlling pests (Finley et al., 2018). However, the novel COVID-19 that causes the social distancing measure has placed a significant concern on farmers about a dramatic shortage of paid and exchanged labors as the latter fear of getting this virus (Theparat and Charoensuthipan, 2020). This may force organic rice production to stand on the edge of insecurity. Even before the arrival of COVID-19, fears about labor shortages in the organic sector have been mounting resulted from the fact that Thai workers do not usually want to work in the agricultural industry due to its hard tasks (Choenkwan and Fisher, 2018).

Admittedly, in agricultural communities, there is no perfect solution fitting all problems as a solution depends on the social-ecological contexts in which the problem is generated. A workable solution is resilience. This concept proposes an efficient framework to understand the complicated relationships between humans and the environment, and offers practical actions against the dynamic change of social-ecological systems (SESs) (Dixon and Stringer, 2015). Therefore, people who are installed with resilience tend to have location-specific adaptation and transformation to fit with unpredictable pressures (Brunner and Regamey, 2016).

Because resilience is about adaptation, components of skills and assets are imperative for location-specific adaptation and transformation (Carpenter et al., 2001). For example, in comparison with other farming systems, organic farming is more favorable to build resilience because of its qualities to mimic the natural structure to receive the bio-diversification's advantages (IFOAM, 2013). But sometimes the well-beforehand preparation of those components cannot guarantee the everlasting resilience of systems. Resilience is a property that crucially depends on the spatialtemporal evolution process so a tiny change of spatial-temporal settings often leads to a new component required. In times of economic crisis, for instance, farmers are willing to temporarily sacrifice their farm's biodiversity to earn abundant yields; then chemicals are exploited to decrease the loss affected by the outbreak of insect pests. Latter-day when such an economic pressure is relieved to a certain degree, the farmers will nourish biodiversity again to return to the original 
state. Theoretically, this is called transformation. It is system owners' endeavor to balance the interplay of a gradual and abrupt change to substitute the primitive system, which is untenable of social-ecological disruptions at that time, with a more suitable new system for prosperity (IFPRI, 2013).

As mentioned earlier, COVID-19 is the world's worst crisis and its effects are greater than those of WW II and the Great Depression combined (Walsh, 2020). Therefore, it is interesting to investigate how COVID-19 influences the social-ecological resilience of the organic rice production system. In the investigation, not only COVID-19's impacts on organic rice production are addressed, but organic farmers' transformation and essential components in dealing with the pandemic are also identified. The latter is vital. It provides a broad set of guidance for stakeholders to execute if in the future this sort of pandemic will arise again.

\section{Literature Review}

\subsection{The rationale of resilience}

The theory of resilience was first addressed by Holling (1973) as the persistence of a system and its ability to absorb or tolerate perturbations and still maintain the same essential regime as a result of the existence of the capacities of learning and adaptation including a high degree of selforganization and network connectedness. These properties are dubbed as the three vital qualities to build the resilience system because it is compiled in adaptability based on iterative, and experimental procedures and decision making (Holling, 2001). Since that resilience and its related concepts, especially with the lens of the environment, have been popularly spread in many disciplines proved by the last twenty years the number of resilience articles has increased from around 250 publications to moreover 6,000 publications (Folke, 2016). The academic popularity is because of two principal reasons. First, resilience is a dynamic concept emphasizing on how to persist with change and how to evolve with change. Also, resilience has become an indispensable part of policies and practices, ranging from sustainable development to political schemes for generating an efficient framework or a set of practical skills against all kinds of change and crisis occurred at the local scale to the global scale (Jiggins and Rölling, 2000).

When the resilience studies were examined methodically, there are four vital features that interact across temporal and spatial scales necessary for building, enhancing, and understanding the complexity of general social-ecological resilience systems to consider (Folke et al., 2010). These features are significant for resilience studies. They authorize all kinds of dynamic shocks, including resilience properties such as diversity, modularity, openness, reserves, feedbacks, leadership, and trust to be seen and measured tangibly (Carpenter et al., 2001). These four vital features are:

(1) Learning to live with change and uncertainty, which relates to the importance of acknowledging dynamic surprises in a way that shows confidence. Such surprises must be considered as advantages for lifelong learning and introducing opportunities for social-ecological development in tune with the biosphere.

(2) Nurturing diversity in its various forms. Generally, this feature illuminates the significance of nurturing a variety of diversity to be applied as insurance against unexpected uncertainty. Also, diversity is more important than insurance as it provides several components and its history that create innovative evolution after perturbation.

(3) Combining different types of knowledge and learning. It is apparent that peoples' knowledge, skills, experience, and understanding about their social-ecological systems are indispensable to attain strategic implementations, including suitable decisions and solutions.

(4) Creating opportunities for self-organization and cross-scale linkages. The fourth amalgamates those mentioned features in the context of self-organization at multiple levels, which includes internal and external actors to develop reflective actions and transformative practices for navigating uncertainty (Tilt, 2016).

The four features' processes encompass practices and skills and qualifications, including social mechanisms to prevent resilience loss (Folke, 2006). Therefore, this qualification is not only efficient to apply quantitatively such as assessing and monitoring but also to qualitatively guide the 
sustainable way of reducing vulnerability through adaptation and transformation during a period of dynamic change (Endfield, 2012).

\subsection{Impacts of the COVID-19 pandemic on Thai agriculture}

Originally, 2020 was considered a challenging year for Thailand's agriculture due to the retardation of the world economy and severe droughts and floods occasionally occurred throughout the year. However, this situation has been worse than ever since the outbreak of the pandemic that has caused the country's economic turmoil in most sectors, especially agricultural sectors, whose supply chain has stakeholders and is largely relied on the overseas markets. According to a TMB report (2020), even the overall prices of agricultural products are predicted to increase by $2.1 \%$, but at the same time the demand for Thai agricultural products is dwindled by the pandemic as a result of the planned distribution outlets were blocked. Consequently, Thai farmers' income is expected to decline by around $0.6 \%$

One of the stakeholders who have been vulnerable to such a pandemic is organic farmers. The difficulty takes place towards them owing to the closure of green markets and logistics restrictions, including the lack of access to the desire number of labors. Especially the latter that makes organic farming susceptible. This factor not only affects the quality control of organic farming but also the short-term failure of the production as a result of organic farming in Thailand is prominently operated by elder farmers. When numbers of labor are unattainable resulted by lockdowns, farm manual tasks like planting or weeding are arduous to achieve production efficiency due to the absence of labor migration (Cullen, 2020). Even hiring types of mechanization such as tractors to engage in on-farm activities were difficult. Tractor drivers stopped working due to the fear of the epidemic or the lockdown policies.

These are unaccommodating for organic farmers as individuals solely. It also raises concerns over the domestic food security in both terms of production and circulation at the larger scale as many on-farm problems driven by the COVID-19 have gradually appeared. For example, in Northern Thailand, many organic farmers could not plant crops on time. Also, they reportedly suffered not only from income loss but also an amount of production intentions, which some had been kept to consume within the household. More importantly, according to the local media, around 7.5 Thai million farmers, who are halted by the virus outbreak, had filed a petition to the government for being given the financial aid of 5,000 THB for 3 months (Bangkok Post, 2020). These issues are the tip of the iceberg. If it remains unsolved, Thai agriculture and their stakeholders' livelihood quality would be more disruptive. Eventually, around 10 million people, who depend on agriculture, are forecast to lose sustainability and to trap in poverty (Nieuwsbericht, 2020).

\section{Methods}

The study was designed to investigate the COVID-19's effects on the social-ecological resilience of the organic rice production system in four districts of Chiang Mai Province namely Mae Rim, Mae Taeng, San Sai, and Phrao, where organic rice production had been predominant (DOAE, 2013). It is an extension of a previous study that emphasized how to utilize knowledge and insights of eight experienced organic farmers whose residences and farms are situated in those four districts to develop a set of components necessary for building the resilience of organic rice production. The results were 47 social-ecological resilience components coupled with an importance weighting to determine their contribution values of resilience building (Panpakdee, 2018). To accomplish the objectives of the present study, the following research methodology and tools are used.

\subsection{Study site}

Mae Rim, Mae Taeng, San Sai, and Phrao were deliberately selected as study sites to be accordant with the previous study (Panpakdee and Limnirankul, 2018; Panpakdee, 2018).

\subsection{Sampling procedure}

Based on the number of organic farmers participating in the previous study (Panpakdee, 2018), the eight experienced organic farmers were selected purposively to accomplish the phenomena of 
interest. However, a male organic farmer in Mae Rim existing in the original study was not included this time as he had passed away. His wife, who has inherited the farm, was thus chosen to substitute as the informant.

\subsection{Data collection}

From June to July 2020, a questionnaire was administered to collect data at the farm level. The eight organic farmers as informants were structurally interviewed about the topics consisting of how the ongoing COVID-19 affects their organic rice production's social-ecological resilience and what adaptations (strategies, thinking orientation, and practices) facilitated by the 47 resilience components were deployed to mitigate the pandemic's pressures. Such a quantitative method was simultaneously employed with the longitudinal case analysis. The latter was applied to enable indepth exploration and analysis of social phenomena in real-time to collect data in a style of retrospective studies (Pucci et al., 2020). The collected data were used as a fundamental source to provide the explicitly narrative results and to identify the eight informants' changes in behaviors, thoughts, and attitudes that could affect their resilience over a period of the pandemic time (Langley et al., 2013).

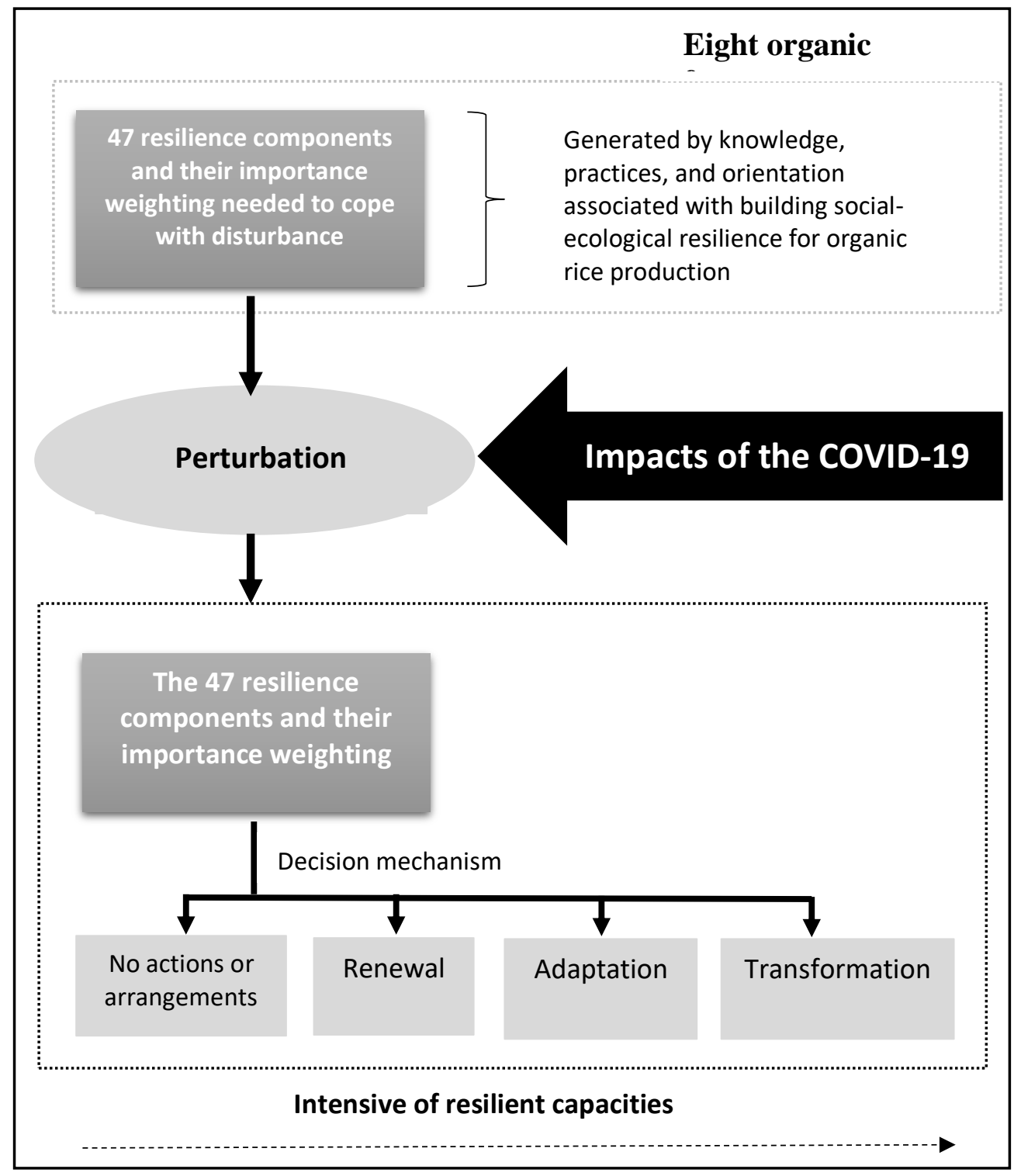

Figure 1. A conceptual framework for assessing impacts of the COVID-19 towards eight organic farmers' social-ecological resilience

To be noted, amidst the pandemic-related threats, the interviews were still conducted face-toface due to two significant reasons. First, all informants were inconvenient to access types of virtual 
interview technology or video conference, while the phone interview was unaccommodating for this study as the questionnaire's questions need to be explained elaborately for clear comprehension. Second, the face-to-face interview staying at least 6 feet away from the informant was decent to prevent this virus from spreading for the two parties (Shereen et al., 2020).

Next, the informants were asked to assign an importance weighting to the 47 resilience components by rating a single number of the 1-9 fundamental scale (Saaty, 2008). This rating process was specified by the informants' insights and awareness including perception regarding those resilience components' importance intensity contributing to the development of resilience against COVID-19. Also, an intensive field investigation was carried out as well to gather socialecological information that will be useful for the data analysis.

\subsection{Data analysis}

After the rating was completed, the importance weighting scores were computed using the eigenvector (EV) method. In this stage, there were two sets of data available (1) the 47 resilience components paired with importance weighting score that was originally assigned their contribution values of resilience building by the eight experienced organic farmers (Panpakdee, 2018); (2) the 47 resilience components paired with importance weighting score that was recently determined for their contribution values of resilience building by the eight experienced organic farmers. After that, the paired samples t-test was run to compare whether the means difference exists between the two sets of data. Consequently, the finding will inform how the informants' organic rice production was altered due to COVID-19. Also, types of constructive adaptation, factors, and practices needed to continue the production amidst the pandemic, and this sort of disease outbreak were identified as the study's other benefit.

\section{Results}

Table 1 and Table 2 present the findings involving the four vital properties needed for building organic rice production's resilience. It can be seen that the contribution values of all four vital properties were altered for the farmers to cope with the undesirable situations posed by COVID- 19 . This is an expected phenomenon. Normally, farmers as system owners have to introduce adaptation in forms of technology or farming methods that do not affect the production, and are feasible and efficient to implement to survive and to recover from the face of disturbances (Scarborough et al., 2014). For example, in this study, the significant value of the combination of different types of knowledge and learning was increased from 0.26 to 0.27 so was that of the property of nurturing diversity in its various forms from 0.23 to 0.24 because these two properties had recently been key factors influencing adaptive capacities. Meanwhile, the contribution value of learning to live with change was reduced in the presence of the pandemic because this property has been associated with the long-term plans that require investment in time and education, which is not fit for most organic farmers' social-ecological contexts now. However, for statistical interpretation, there is no average difference between the original scores and the latest scores influenced by the pandemic outbreak because of the $p$-value $>0.05$.

On average, the mean of the original scores and the mean of the latest scores are also equal at 0.25 at a $95 \%$ confidence interval $(\mathrm{Cl})$.

Table 1. Comparing the vital resilience properties' means of contribution value before and after COVID-19

\begin{tabular}{lcc}
\hline Vital resilience property & Before COVID-19 & After COVID-19 \\
\hline Learning to live with change and uncertainty & 0.25 & 0.23 \\
Nurturing diversity in its various forms & 0.23 & 0.24 \\
Combining different types of knowledge and learning & 0.26 & 0.27 \\
Creating opportunity for self-organization and cross- & 0.26 & 0.26 \\
scale linkages & & \\
\hline
\end{tabular}


Table 2. Descriptive statistics and paired samples t-test of the vital resilience properties' means before and after COVID-19

\begin{tabular}{lcccccc}
\hline Importance weighting score & $\mathbf{n}$ & mean & SD & $\mathbf{t}$ & $\mathbf{d f}$ & Sig \\
\hline Before COVID-19 & 4 & 0.25 & 0.00 & 0.00 & 3.00 & $1.00^{* *}$ \\
After COVID-19 & 4 & 0.25 & 0.00 & & & \\
\hline
\end{tabular}

**Significant at the 0.05 level

Table 3 presents the average scores of the 47 resilience components before and after COVID19 for comparison. The result is identical to the case of the four vital properties in terms of acceptance of the null hypothesis as the p-value $>0.05$. Also, there is no difference between the mean score for before the COVID-19 period and that for after the COVID-19 period as of $t(3.00)=$ 0.00 .

Table 3. Descriptive statistics and paired samples t-test of the 47 social-ecological resilience components' means before and after COVID-19

\begin{tabular}{lcccccc}
\hline Importance weighting score & $\mathbf{n}$ & mean & SD & $\mathbf{t}$ & df & Sig \\
\hline Before COVID-19 & 47 & 0.31 & 0.02 & 0.00 & 46.00 & $1.00^{* *}$ \\
After COVID-19 & 47 & 0.31 & 0.02 & & & \\
\hline
\end{tabular}

**Significant at the 0.05 level

The results of a detailed investigation on the 47 resilience components are shown in Table 4. Many of these resilience components, exclusively in the two vital resilience properties namely combining different types of knowledge and learning and creating the opportunities for selforganization and cross-scale linkages, were positively adjusted for their contribution values as they can help build a better resilience against the evolving pandemic. For example, from the eight organic farmers' perspective, the importance weighting score of adaptation (no. 28 in Table 4) was unanimously enhanced from 0.18 to 0.21 , or $+16.67 \%$. They were considering adaptive strategies like, for example, altered planning/harvesting dates based on available assets as necessary at present to mitigate the unavailability of reciprocal labor exchange called "long khaek" due to the social distancing guidance. The absence of this Thai rural customary practice affected them severely. The exploitation of one's physical force had always been their privilege in both aspects of obtaining reliable labors and boosting bonds amongst neighboring farmers at the local level.

This is followed by the greater importance of reasonable farm scale and the dependence on household labors. Originally, these two components are about how to operate at a farm size to fit the available household laborers who are willing to work for long hours and in a wide range of tasks in a way that hired laborers are not. In other words, it is about being self-dependent to prevent the organic rice production deterioration posed by labor constraints in needed times. As mentioned earlier, however, the social distancing guidance comes with the difficulty of hiring a large group of workers. Even if workers are willing to be hired, unsurprisingly, they request a higher daily wage as extra compensation for risking their safety. To escape this problem by hiring migrant workers, as usual, was difficult too because of the quarantine concern. Therefore, from the present to the future to survive in such a new normal situation, the farmers scored a greater contribution value of these two components up from 0.21 to 0.23 and 0.19 to 0.23 , or an increase by $9.52 \%$ and $21.05 \%$, respectively.

As COVID-19 generates the obligatory logistics in carrying consumer goods and if such the logistics bounces back to the normal state in the coming future, the questions sent directly to the agricultural food industry will certainly take place especially in the issue of food security. Then the reliance on the local food systems, that on the rice and dietary materials self-produced, and the full trust in local inputs become the three key resilience components that deserve consideration. The dependence on such local products as far as possible not only supports the convenient matter of acquiring wanted materials but also offers a better chance to own consumer goods free from coronavirus contaminations because the locally produced consumer goods are easier for traceability compared to the imported ones. For these reasons, the three resilience components received more 
importance weighting after COVID-19. The contribution value of dependence on local food systems, and that of the trust in inputs at the local level increased from 0.19 to 0.28 and 0.21 to 0.29 respectively. The autonomy of rice and dietary materials self-produced was also higher in value from 0.21 to 0.22 . Note that although owning self-produced food sources was considered essential, its importance weighting was slightly altered upward by $4.76 \%$ because most organic farmers do diversified agriculture that gives them sufficient sources of food. Besides, organizing the recording of household accounts got an increase in the contribution value by $31.85 \%$, from the original 0.22 to the new 0.29 .

On the other hand, six resilience components got a lower importance weighting score consequential to the COVID-9 outbreak. The majority of them are elements of the vital resilience property of creating opportunities for self-organization and cross-scale linkages while the rest are associated with the combination of different types of knowledge and learning (Berkes, 2009).

From the informants' viewpoint, the social distancing protocol was responsible for the reduction of the six components' degree of importance. Since COVID-19 is transmitted from the infected persons to other people mostly through the respiratory droplets, keeping a physical distance from others is the best-recommended way to control the spread of this disease. Consequently, many practices regularly executed in normal time to support the organic rice production resilience were halted. For example, co-operative farming (no.42), knowledge exchange through networks (no.43), and reciprocal labor exchange (no.46) became unworkable. The reasons are simple. These practices require the gathering of more than two people at a close range. In case a farmer needed some help from his/her fellow farmers, the traveling was either minimized or restricted by the government's regulations. One organic farmer in Mae Rim District stated that the pandemic not only disrupts the opportunity to meet other organic farmers for some purposes but also deprives the way of life.

"At least 3-5 farmers had been congregating at someone's residence for their morning coffee for the exchange of news and information. This was a long-standing tradition in this community. But from now on, such a practice must be abolished because we are elderly who have a higher risk of exposure to more severe complications from COVID-19 illness." Said he.

Having value-added products (no.26), securing consumer confidence (no.32), and the rice field location (no.41) were all affected by the social distancing protocol too. They were decreased in the contribution value from 0.20 to $0.11(-45.00 \%), 0.19$ to $0.16(-15.79 \%)$, and 0.18 to $0.13(-27.78 \%)$, respectively. In short, the three resilience components involve how to strengthen the household economy by producing processed products, which will provide an income two to three times higher than selling farm output as raw materials, for distribution to important outlets within the province to attract consumers interest as local products. Nevertheless, they were adjusted downward in contribution value because of the social distancing requirement. Likewise in other activities, laborers are indispensable in a supply chain of manufactured value-added products such as ricebran oil and pre-germinated rice. Although manufacturers are possible to hire any number of workers required, the chance to do the commercial-scale production, as usual, seems unlikely at this time due to the closure of markets and fears of catching the virus amongst the stakeholders.

Table 4 Comparing 47 resilience components' importance weighting scores before and after COVID-19

\begin{tabular}{|c|c|c|c|c|c|}
\hline $\begin{array}{l}\text { The broad concept of } \\
\text { resilience }\end{array}$ & Resilience component & $\begin{array}{c}\text { Before } \\
\text { COVID-19 }\end{array}$ & $\begin{array}{c}\text { After } \\
\text { covID-19 }\end{array}$ & Difference & $\begin{array}{c}\% \\
\text { Change }\end{array}$ \\
\hline 1. Preparing & 1) Educational level & 0.23 & 0.23 & 0.00 & 0.00 \\
\hline themselves for & 2) Rice & 0.26 & 0.26 & 0.00 & 0.00 \\
\hline unpredictable & experience & 0.28 & 0.28 & 0.00 & 0.00 \\
\hline events & 3) Occupational skills & 0.23 & 0.23 & 0.00 & 0.00 \\
\hline & $\begin{array}{l}\text { 4) Gender equality } \\
\text { Total }\end{array}$ & 1.00 & 1.00 & 0.00 & \\
\hline 2. Reasonable & 5) Investment in farm & 0.54 & 0.54 & 0.00 & 0.00 \\
\hline $\begin{array}{l}\text { investment } \\
\text { reduce risks }\end{array}$ & assets & 0.46 & 0.46 & 0.00 & 0.00 \\
\hline
\end{tabular}




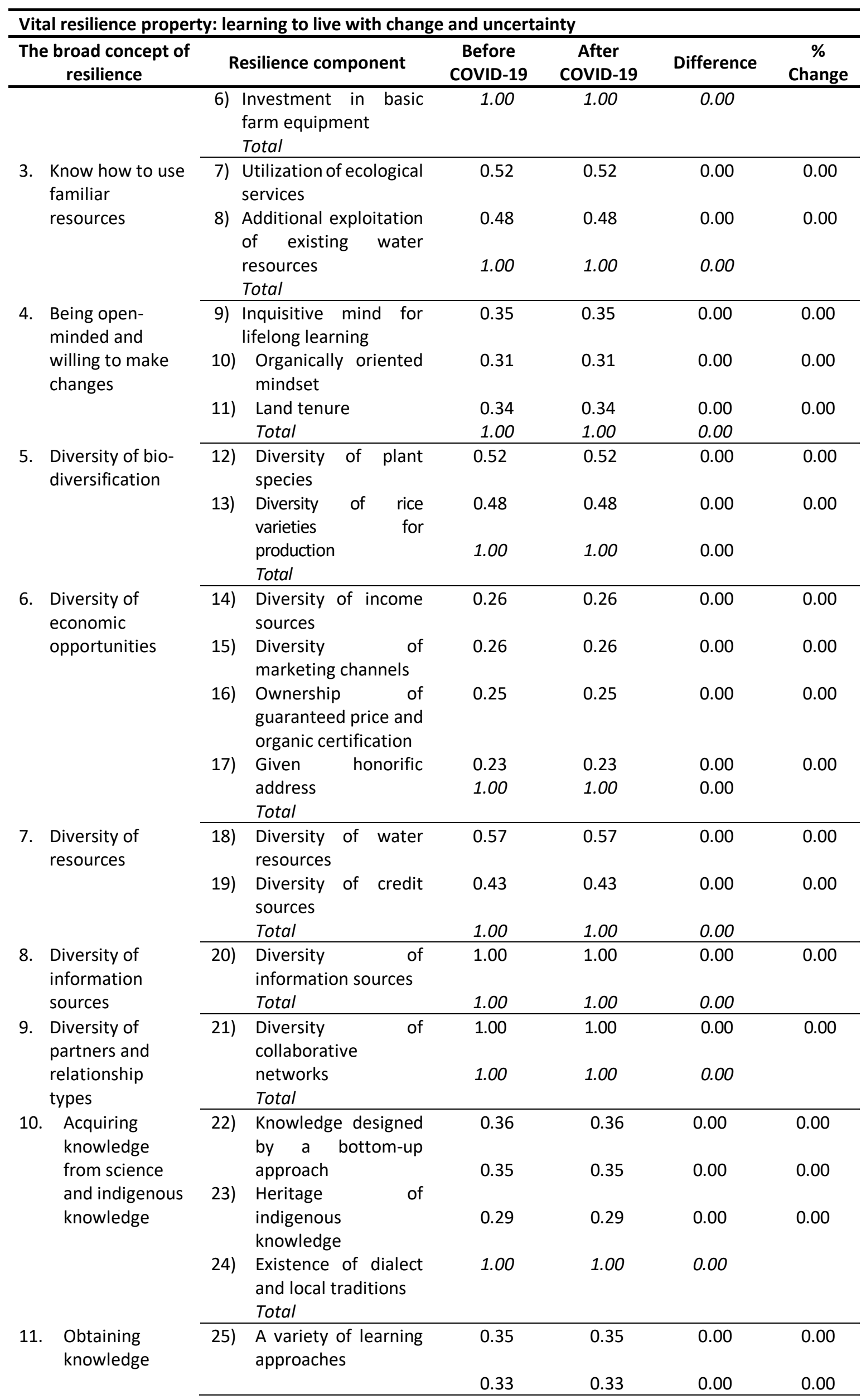




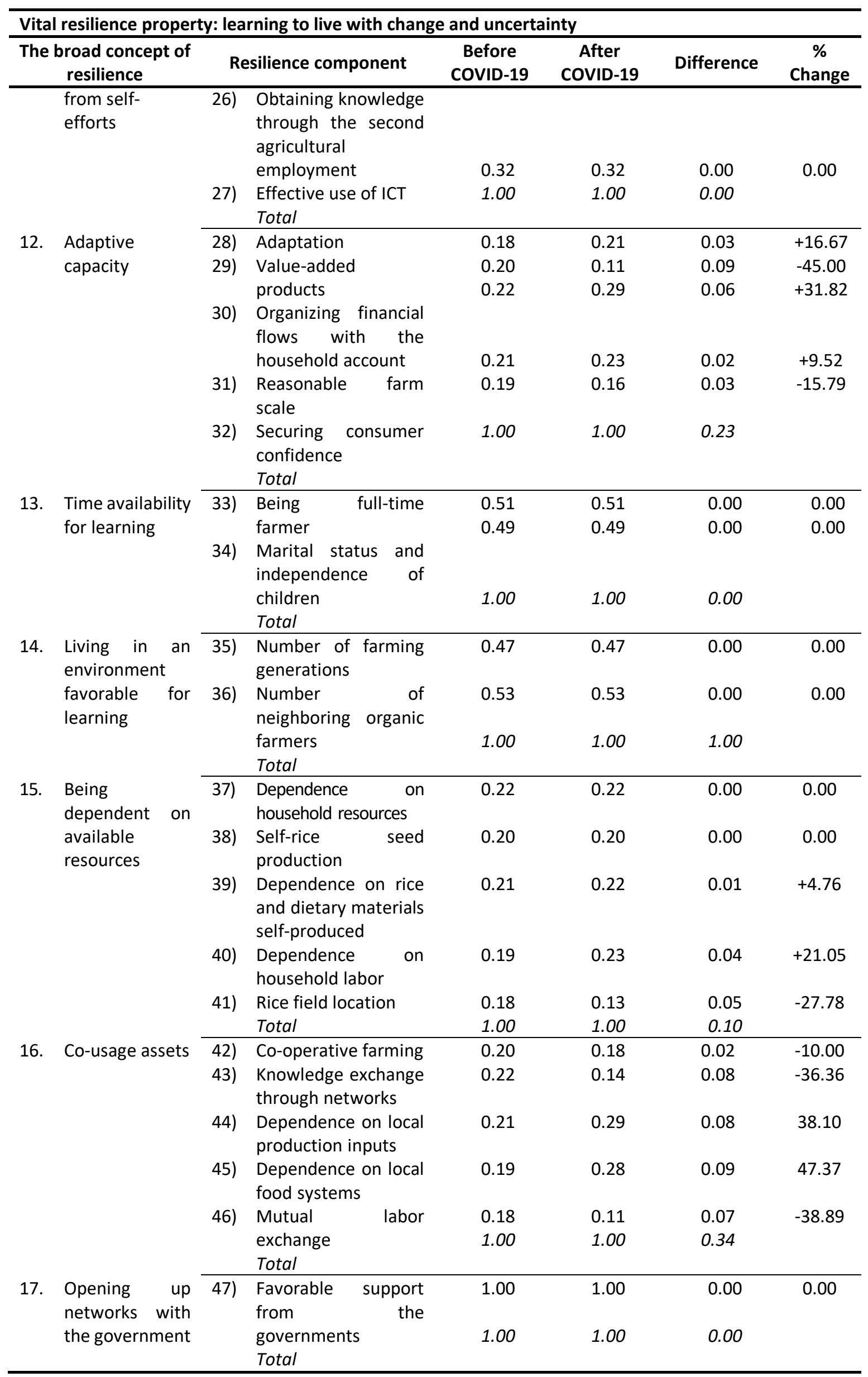




\section{Discussion and Conclusion}

As far as everybody knows, COVID-19 is an enormous shock to the world, and the cost is not only unpredictable but also unbearable to all humans involved. While governments at the policy level have been racing to address the issues unceasingly posed by the pandemic, a small group of organic farmers in four districts of Chiang Mai Province is witnessed already preparing for incessant change.

According to the finding, the eight organic farmers are endeavoring to be the greatest selfreliant in various ways for being given resources to endure the pandemic's aftermath. For example, since the pandemic has begun, the components of adaptation and household accounts recording were heightened in their contribution values because these resilience components are considered as primary tools required to withstand the evolved challenges. Regarding adaptation, it is found fewer rice varieties are being planted this season, and vegetables after rice harvest will likely be in the same way. Such adaptation is necessary to avoid the labor shortage posed by the social distancing protocol. Meanwhile, the recording of household accounts was given an increased importance weighting as well. In the time of financial vulnerability at present, the household accounts will show in detail for farmers to be aware of how much money was paid and whether or not the rest is sufficient for the family living needs. In other words, wise spending and proper familyliving adjustments to meet usual lower incomes can be advised by the household accounts recording. Also, self-local autonomy is adopted. Although most informants are deliberately diversified farmers to receive bio-diversification's benefits (Koohafkan et al., 2012), it is not sensible to produce all consumer goods themselves to meet their demands. Therefore, to get connected with neighbors is vital to obtain the desired goods, and the feasibly virus-free goods that can be claimed because they are produced by local trustworthy persons and there is less chance of consumers' exposure to contaminants in the absence of transportation (Ortiz-Miranda et al., 2010).

At the same time, many components became shaky to be the powerful factor to build the resilience of organic rice production. To produce value-added products, to get supports, and to exchange knowledge from co-operative networks including exchanging mutual labors are the instances. Apparently, all of these have been affected by the social distancing protocol that causes complications on the supply chain's activities due to disturbed logistics, organic markets closing, and people gathering prohibition.

From the examples above, it is clear that COVID-19 is affecting organic rice production as the organic farmers have to make changes to navigate the transition to achieve resilience of the new trajectory of development. Importantly, whether COVID-19 is present or not, the process of making change has been continual as long as the uncertainty is one of the few certainties in life. It is predictable someday the component of mutual labor exchange and others will be altered in terms of the contribution value if a COVID-19 vaccine is not yet available. As mentioned earlier, they are key ingredients to empower the organic rice production, especially in the resilience of labor management and agricultural community strengths (Berkes and Ross, 2013).

Lastly, the authors are aware that this study doubts to summarize that organic rice production's resilience is being interrupted by the pandemic: The paired samples t-test results indicate that there is no statistically significant difference between the before COVID-19 period and the after COVID-19 period for both the four vital resilience properties and the 47 components. There are explanations to clarify that result as in the following.

1) Beginning with the four vital resilience properties, based on resilience theories (Folke, 2006; Gallopin, 2006; Tilt, 2016), they are all fundamental to generate resilience and adaptation and reorganization during times of drastic change. However, they have been without particularizing which property is more significant than the others. Therefore, it is impractical both practically and theoretically to determine the statistically different means of any pre-events and post-events associated with the four properties.

2) Although the 47 resilience components are a cluster of qualifications, which is expected to vary during times of change as each location needs exclusive attributes to accomplish locationspecific solutions (Folke et al., 2010; Ciftcioglu, 2017), the results in Table 3 still state that their 
means before and after the COVID-19 outbreak are not different statistically. This is because COVID19 was reportedly first identified in December 2019 (Huang et al., 2020). But in Thailand, this pandemic was announced to be controlled by the state of emergency in late March 2020 (Bangkok Post, 2020). Only three months since the pandemic has domestically diffused, it is the organic farmers' cognitive barrier to make significant changes. Particularly what were not changed are the components of learning to live with change and uncertainty, and nurturing diversity in its various forms, which have been primarily involved with the long-term plan to build alternatives and strategies for self-empowerment (Darnhofer, 2010).

3) Because becoming resilient is a multi-step process involved in dimensions, but in reality, some processes of change are deliberately terminated by change agents' constraints instead of incidents (Anderson and D'souza, 2014). In this study, most organic farmers have realized online marketing to access the mass scale is the solution to counter the closure of traditional markets. However, the component of the effective use of ICT (no.27 in Table 4) is still unchanged as the application of ICT technologies to manage such e-commerce is difficult to breakthrough.

4) Because individuals' resilience state is always movably influenced by temporal and spatial dimensions of a system, it is recommended to monitor the change by the questionnaire survey paired with longitudinal methods. The combination of these dual methods tailored appropriately will provide a framework for questioning and observing, which is suitable in the field. Consequently, the efficiency in detecting the target population's resilience fluctuation is revealed. If researchers want to go this route, however, they have to be aware of that system's components and structures to identify what kind of abundant data is useful to them including explicit feedback to accomplish time economy (Thomas, 2020).

Acknowledgments: This study was funded by the Research Administration Division of Khon Kaen University. The authors would like to thank all participating organic farmers in the study sites for their full support.

Conflicts of interest: The authors declare no conflict of interest

Ethical statement: We declare that this manuscript is original, has not been published before, and is not currently being considered for publication elsewhere. We wish to confirm that there are no known conflicts of interest associated with this publication and there has been no significant financial support for this work that could have influenced its outcome. Also, we further confirm that the manuscript has been read and approved by all named authors and that there are no other persons who satisfied the criteria for authorship but are not listed. Lastly, we confirm that any aspect of the work covered in this manuscript does not contain any studies with human participants or animals performed by any of the authors.

\section{References}

Anderson, J.A., \& D'souza, S. (2014). From adoption claims to understanding farmers and contexts: A literature review of conservation agriculture (CA) adoption among smallholder farmers in Southern Africa. Agriculture, Ecosystems and Environment, 187, 116-132. https://doi.org/10.1016/j.agee.2013.08. 008

Anderson, K., \& W. Martin. (2009). Distortions to Agricultural Incentives in Asia. Washington, D.C.: World Bank.

Bangkok Post. (2020). Curfew starts on Friday: All travel to nation halted for 2 weeks. Retrieved from https://www.bangkokpost.com/thailand/general/1891910/curfew-starts-today

Bangkok Post. (2020). 73,000 farmers to receive Covid-19 aid on appeal. Retrieved from https://www.bangkokpost.com/thailand/general/1946924/73-000-farmers-to-receive-covid19-aid-on-appeal

Berkes, F. (2009). Evolution of co-management: Role of knowledge generation, bridging organizations and social learning. Journal of Environmental Management, 90(5), 1692-1702. https://doi.org/10.1002/jid.2992

Berkes, F., \& Ross, H. (2013). Community Resilience: Toward an Integrated Approach. Society and Natural Resources, 26(1). https://doi.org/10.1080/08941920.2012.736605 
Boone, L., Roldan-Ruiz, I., Van linden, V., Muylle, H., \& Dewulf, J. (2019). Environmental sustainability of conventional and organic farming: Accounting for ecosystem services in life cycle assessment. Science of the Total Environment, 695(10): 133841. https://doi.org/10.1016/j.scitotenv.2019.133841

Bouttes, M., Darnhofer, I., \& Guillaume, M. (2018). Converting to organic farming as a way to enhance adaptive capacity. Organic Agriculture, 9, 235-247. https://doi.org/10.1007/s13165-018-0225-y

Brunner, S. H., \& Regamey, A. G. (2016). Policy strategies to foster the resilience of mountain socialecological systems under uncertain global change. Environmental Science and Policy, 66, 129139. https://doi.org/10.1016/j.envsci.2016.09.003

Carpenter, S., Walker, B., Anderies, J. M., \& Abel, N. (2001). From metaphor to measurement: Resilience of what to what? Ecosystems, 4, 76-81. https://doi.org/10.1007/s10021-001-00459

Choenkwan, S., \& Fisher, M. (2018). Introduction to the special section: Agrarian transformation in Thailand -Commodities, landscapes, and livelihoods. Forest and Society, 2(2), 112-120. http://dx.doi.org/10.24259/fs.v2i2.5356

Ciftcioglu, G. C. (2017). Assessment of the resilience of socio-ecological production landscapes and seascapes: A case study from Lefke region of North Cyprus. Ecological Indicators, 73, 128-138. https://doi.org/10.1016/j.ecolind.2016.09.036

Cullen, M. T. (2020). COVID-19 and the risk to food supply chains: How to respond? Rome: FAO. https://doi.org/10.4060/ca8388en

Darnhofer, I. (2010). Strategies of family farms to strengthen their resilience. Environment Policy and Governance, 20, 212-222. https://doi.org/10.1002/eet.547

Dixon, J. L., \& Stringer, L. C. (2015). Towards a theoretical grounding of climate resilience assessments for smallholder farming systems in Sub-Saharan Africa. Resources, 4, 128-154. https://doi.org/10.3390/resources4010128

DOAE. (2013). Basic agricultural information of Chiang Mai province 2012. Chiang Mai: DOAE.

Endfield, G. H. (2012). The resilience and adaptive capacity of social-environmental systems in colonial Mexico. Proceeding of the National Academy of Sciences of the United States of America, 109(10), 3676-3681. https://doi.org/10.1073/pnas.1114831109

Finley, L, Chappell, J. M., Thiers, P., \& Moore, J. R. (2018). Does organic farming present greater opportunities for employment and community development than conventional farming? A survey-based investigation in California and Washington. Agroecology and Sustainable Food Systems, 42(5), 552-572. https://doi.org/10.1080/21683565.2017.1394416

Folke, C. (2006). Resilience: The emergence of a perspective for social-ecological systems analyses. Global Environmental Change. 16: 53-67. https://doi.org/10.1016/j.gloenvcha.2006.04.002

Folke, C. (2016). Resilience (Republished). Ecology and Society, 21(4), 44. https://doi.org/10.5751/ES-09088-210444

Folke, C., Carpenter, S., Walker, B., Scheffer, M., Chapin, T., \& Rockstrom, J. (2010). Resilience thinking: Integrating resilience, adaptability and transformability. Ecology and Society, 15, 20. https://doi.org/10.5751/ES-03610-150420

Gallopin, G. (2006). Linkages between vulnerability, resilience and adaptive capacity. Global Environmental Change, 16(3), 293-303. https://doi.org/10.1016/j.gloenvcha.2006.02.004

Green Net. (2014). Organic Production Areas in Thailand. Retrieved from http://www.agriqua.doae.go.th/organic/oa\%20produce/thai.html.

Holling, C. S. (1973). Resilience and stability of ecological systems. Annual Review of Ecology and Systematics, 4, 1-23. https://doi.org/10.1146/annurev.es.04.110173.000245

Holling, C. S. (2001). Understanding the complexity of economic, ecological, and social systems. Ecosystem, 4, 390-405. https://doi.org/10.1007/s10021-00 -0101-5

Huang, C., Wang, Y., Li, X., Ren, L., Zhao, J., Hu, Y., \& et al. (2020). Clinical features of patients infected with 2019 novel coronavirus in Wuhan, China. Lancet, 395(10223), 497-506. https://doi.org/10.1016/s0140-6736(20)30183-5

IFOAM. (2013). Principles of organic agriculture. Bonn: IFOAM.

IFPRI. (2013). Agricultural Resilience in the Face of Crisis and Shocks. Brussels: IFPRI. 
Jiggins, J., \& Rölling, R. (2000). Adaptive management: Potential and limitations for ecological governance. International Journal of Agricultural Resources, Governance, and Ecology, 1(1), 28-42. https://doi.org/10.1504/IJARGE.2000.000003

Langley, A., Smallman, C., Tsoukas, H., \& Van de Ven, A. H. (2013). Process Studies of Change in Organization and Management: Unveiling Temporality, Activity, and Flow. Academy of Management Journal, 56(1), 1-13. https://doi.org/10.5465/amj.2013.4001

Koohafkan, P., Altieri, M.A., \& Gimenez, E.H. (2012). Green agriculture: Foundations for biodiverse, resilient and productive agricultural systems. International Journal of Agricultural Sustainability, 10, 61-75. https://doi.org/10.1080/14735903.2011.610206

Limnirankul, B., \& Gypmantasiri, P. (2011). Agricultural innovation in supporting organic rice production system of smallholder farmers in Northern Thailand (Research Report). Thailand: National Science and Technology Development Agency.

Nieuwsbericht. (2020). Update on COVID-19 impact in Thailand. Retrieved from https://www.agroberichtenbuitenland.nl/actueel/nieuws/2020/04/28/update-on-covid-19impact-in-thailand

Ortiz-Miranda, D., Moreno-Perez, O.M., \& Moragues-Faus, A.M. (2010). Innovative strategies of agricultural cooperatives in the framework of the new rural development paradigms: The case of the Region of Valencia (Spain). Environment and Planning A: Economy and Space, 42, 661677. https://doi.org/10.1068/a42168

Panpakdee, C. (2018). Social-ecological resilience of smallholder farmers for organic rice production in Chiang Mai Province (Doctoral dissertation). Chiang Mai University, Chiang Mai, Thailand.

Panpakdee, C., \& Limnirankul, B. (2018). Indicators for assessing social-ecological resilience: A case study of organic rice production in northern Thailand. Kasetsart Journal of Social Sciences, 39(3), 414-421. https://doi.org/10.1016/j.kjss.2017.07.003

Pattanapant, A., \& Shivakoti, G. P. (2009). Opportunities and constraints of organic agriculture in Chiang Mai Province, Thailand. Asia-Pacific Development, 16(1), 115-147. https://doi.org/10.18356/341adb3e-en

Pucci, T., Casprini, E., Galati, A., \& Zanni, L. (2020). The virtuous cycle of stakeholder engagement in developing a sustainability culture: Salcheto winery. Journal of Business Research, 119, 364376. https://doi.org/10.1016/j.jbusres.2018.11.009

Ratanapongsai, Y. (2020). Seedling Recruitment of Native Tree Species in Active Restoration Forest. Forest and Society, 4(1): 243-255. http://dx.doi.org/10.24259/fs.v4i1.9421

Rattanasuteerakul, K., \& Thapa, G. (2012). Status and financial performance of organic vegetable farming in Northeast. Land Use Policy, 29: 456. https://doi.org/10.1016/j.landusepol.2011.09.004

Rousseau, S., \& Vranken, L. (2013). Green market expansion by reducing information asymmetries: Evidence for labeled organic food product. Food Policy, 40, 31-34. https://doi.org/10.1016/j.foodpol.2013.01.006

Saaty, T. L. (2008). Relative measurement and its generalization in decision making why pairwise comparisons are central in mathematics for the measurement of intangible factors. Statistics and Operations Research, 102(2): 251-318. https://doi.org/10.1504/IJSSci.2008.01759

Scarborough, G., Mendez, E. V., \& Bisson, A. (2014). Agroecological risk and resilience screening tool: guidance for considering agroecological impact of agriculture interventions and identifying opportunities to build resilience in food systems. Portland, OR: Mercy Corps. https://doi.org/10.13140/RG.2.1.4516.6807

Shereen, M. A., Khan, S., Kazmi, A., Bashir, N., \& Siddique, R. (2020). COVID-19 infection: Origin, transmission, and characteristics of human coronaviruses. Journal of Advanced Research, 24, 91-98. https://doi.org/10.1016/j.jare.2020.03.005

Stuart, A. and Werayutwattana, T. (2017). Understanding the complexities of organic farming in Thailand. 
Theparat, C. \& Charoensuthipan, P. (2020). Royal water project to reinvigorate farming: Social initiative helps workers laid off amid pandemic. Bangkok: Bangkok Post.

Thomas, L. (2020). What is a longitudinal study?. Retrieved from https://www.scribbr.com/methodology/longitudinal-study/

Tilt, B. (2016). Dams and population displacement on China's Upper Mekong River: Implications for social capital and social-ecological resilience. Global Environmental Change, 36, 153-162. https://doi.org/10.1016/j.gloenvcha.2015.11.008

TMB. (2020). Industry analysis: Thai agriculture outlook after Covid-19. Bangkok: TMB.

Walsh, B. (2020). Covid-19: The history of pandemics. London: BBC. Retrieved from https://www.bbc.com/future/article/20200325-covid-19-the-history-of-pandemics

WWF. (2020). FLR349 supports marginalized communities during COVID-19 pandemic fallout. Retrieved from https://www.wwf.or.th/en/project_in_thailand/iki_scp/?uNewsID=362635 